\title{
Mitral endocarditis: A new management framework
}

Francesco Nappi, MD, ${ }^{\mathrm{a}}$ Cristiano Spadaccio, MD, PhD, ${ }^{\mathrm{b}, \mathrm{c}}$ Julien Dreyfus, MD, ${ }^{\mathrm{d}}$ David Attias, MD, ${ }^{\mathrm{d}}$ Christophe Acar, $\mathrm{MD}, \mathrm{PhD},{ }^{\mathrm{e}}$ and $\mathrm{Ko}$ Bando, $\mathrm{MD}, \mathrm{PhD}^{\mathrm{f}}$

From the ${ }^{\mathrm{a} C a r d i a c}$ Surgery Centre Cardiologique du Nord de Saint-Denis, Paris, France; ${ }^{\mathrm{b}}$ Department of Cardiothoracic Surgery, Golden Jubilee National Hospital, Clydebank, Glasgow, United Kingdom; ' ${ }^{\mathrm{C}}$ University of Glasgow Institute of Cardiovascular and Medical Sciences, Glasgow United Kingdom; ${ }^{\mathrm{d}}$ Cardiology department

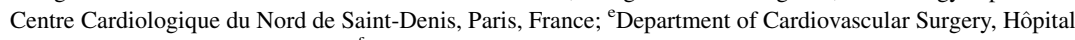
de la Salpétrière, Paris, France; and ${ }^{\mathrm{f}}$ Department of Cardiac Surgery, The Jikei University School of Medicine, Tokyo, Japan.

Received for publication Nov 9, 2017; revisions received March 17, 2018; accepted for publication March 30, 2018; available ahead of print June 5, 2018.

Address for reprints: Francesco Nappi, MD, Cardiac Surgery Centre Cardiologique du Nord de Saint-Denis, 36 Rue des Moulins Gémeaux, Paris 93200, France (E-mail: francesconappi2@ gmail.com).

J Thorac Cardiovasc Surg 2018;156:1486-95

$0022-5223 / \$ 36.00$

Copyright $₫ 2018$ by The American Association for Thoracic Surgery

https://doi.org/10.1016/j.jtcvs.2018.03.159

Supplemental material is available online.

Video clip is available online.

\section{SURGERY FOR MITRAL VALVE ENDOCARDITIS: WHY TREAT? \\ The Clinical Problem}

Mitral valve endocarditis (MVE) is defined as an infection of the entirety or portion of one or both mitral valve leaflets. It can be caused by different pathogens, but bacterial origin is the most common. In developed countries, infective endocarditis (IE) is one of the most common causes of acute mitral valve failure. In some reports, the estimated annual prevalence of IE was 3 to 9 cases per 100,000 persons, and $40 \%$ of those involve the mitral valve with valve failure. ${ }^{1-3}$

Age, shock, prosthetic valve endocarditis (PVE), left ventricular ejection fraction less than $40 \%$, and recurrent endocarditis are considered significant predictors of mortal-

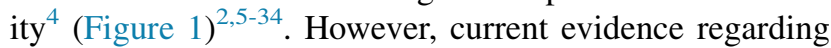
the treatment and management strategy for MVE are not univocal and are often based on personal experiences. We therefore reviewed the literature and developed a systematic approach to endocarditis management centered on the clinical, microbiological, and anatomopathological variables known to affect postoperative outcomes. The final aim was to stratify the patients to assist decision making. We propose the systematic use of a coordinated multidisciplinary approach in the diagnostic workup of

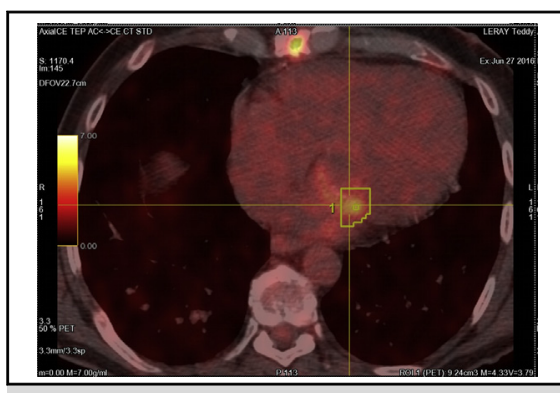

${ }^{18} \mathrm{~F}$-FDG-labelled leucocyte PET-CT scan showing endocarditic focus.

\section{Central Message}

We propose a systematic approach that considers the etiology, clinical presentation, and anatomic extension of the infection to facilitate decision making in mitral endocarditis.

\section{Perspective}

There is no consensus regarding the optimal surgical management of mitral endocarditis. A systematic approach based on the current evidence that accounts for the clinical and anatomopathological variables known to affect postoperative outcomes is proposed. A similar structured framework could more efficiently orient the indications, timing of surgery, and operative strategy to be adopted.

See Editorial Commentary page 1496.

MVE and reinforce the need for early surgical referral, especially when, notwithstanding the appropriate antibiotic therapy, conditions of high-risk of embolization or clinical deterioration are evident (Figure E1).

\section{MULTIDISCIPLINARY TEAM APPROACH FOR MITRAL VALVE ENDOCARDITIS: WHY IS IT SO IMPORTANT?}

The timing of surgery is crucial for patients with native valve endocarditis (NVE) or PVE. Delaying surgery often increases both the probability of complications and the operative mortality and morbidity. Unfortunately, most surgeons find that cardiologists or other hospitals refer patients with IE only after failure of medical therapy, when patients are in intractable heart failure, or when patients have experienced extensive stroke or multisystem organ failure. In some instances, there is not a comprehensive understanding of the surgical challenges, the consequent complications, 


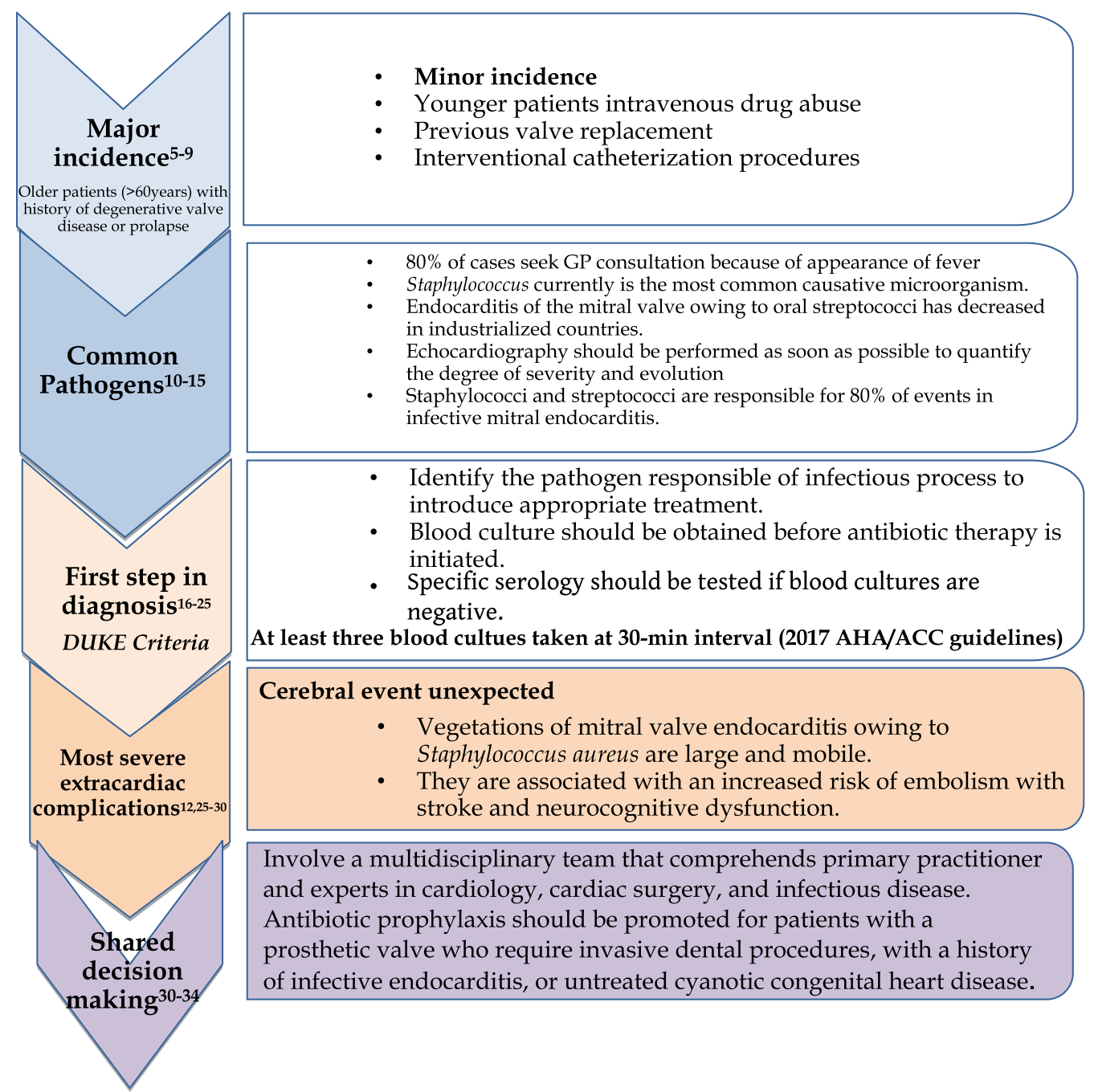

FIGURE 1. Clinical evaluation and diagnosis flowchart (see Supplement Appendix). GP, General practitioner; AHA, American Heart Association; ACC, American College of Cardiology.

and the clinical course of these cases after the operation; combined with the difficulty in identifying the pathogen, this leads to delay in surgical referral with patients offered for surgery at a late stage in significantly compromised clinical conditions and higher intraoperative risk. The early involvement of an experienced cardiac surgeon is thus essential to determine the optimal surgical option and timing to provide the best outcome for patients with MVE. For example, the rate of stroke is significantly higher during the first 2 weeks of antibiotic therapy and in those with left-sided IE, particularly in the mitral position. Moreover, the possibility to perform mitral valve repair instead of replacement can only be explored after dedicated discussion among experienced surgeons and echocardiologists. Because mitral valve repair can provide better long-term survival and functional outcome over valve replacement, ${ }^{35}$ a heart team approach becomes vital to the success of MVE treatment. In this context, the use of the Society of Thoracic
Surgeons (STS) risk scoring system is a valid adjunct in the discussion with the other colleagues as objectifying the operative risk and allowing a better perception of the intraoperative risk. Infectious disease specialists should also be part of a team that provides critical expertise, including the choice of the appropriate antibiotics or antifungal agents and their adequate timing and dose. These specialists can also serve as valuable resources in the management of antibiotic-resistant organisms or complications associated with the prolonged administration of antibiotics. Specialists in internal medicine, nephrologists, obstetricians, and geriatricians should be part of the heart team. In any case, the decision making deriving from such a multidisciplinary approach must be centered on the patient's individual characteristics, and the relative specialist should address special circumstances. Drug abusers constitute a significant portion of the endocarditis population, and the advice of a microbiologist along with specific counseling should be foreseen in 
the workup of these cases. Young women of childbearing age deserve specific consideration, especially if valve replacement is needed. In these patients, anticoagulants are contraindicated and specific counseling and discussion regarding the strategy for valve replacement is needed. Similarly, patients who require long-term dialysis should be assessed preoperatively by the nephrologist, and a plan regarding hemofiltration in the immediate postoperative phase should be discussed.

\section{WHEN TO TREAT?}

The indications and timing of surgery in endocarditis are debated. Despite the fact that the majority of reports comparing surgery versus medical therapy are singlearmed observational studies, there are conflicting conclusions on the benefit of surgery for IE and its timing. ${ }^{36} \mathrm{In}$ addition, no major randomized clinical trial comparing mitral valve surgery with medical therapy has shown a survival benefit over medical therapy in emergency cases.

A recent randomized trial comparing early surgery (within 48 hours) versus medical therapy in 76 patients with severe left-sided IE (ie, large vegetations), but no indications for emergency surgery, revealed a significant lower in-hospital mortality or systemic embolization rate in the surgery group compared with the conventional medical treatment group ( $3 \%$ vs $23 \%$ ). This study supported the idea that, despite the increased operative risk, early surgery in case of IE with large vegetations resulted in a reduction in the composite endpoints of death from any cause and embolic events by effectively decreasing the risk of systemic embolism. ${ }^{37}$ These findings have been confirmed in the long-term follow-up of the same study. ${ }^{38}$ In surgically treated patients, hospital survival was $90 \%$, and outcomes within 30 days were better for NVE than for PVE $(5.6 \%$ vs $13 \%$ ) with similar long-term outcomes (35\% vs $29 \%$ ). Lastly, Staphylococcus aureus was associated with significantly higher mortality compared with other pathogens. ${ }^{37}$

In the majority of cases, a "cooling-down approach" that allows a full course of antibiotics with a reduction in inflammatory markers and resolution of the septic picture is normally advocated. However, early surgery has also been promoted during the initial phase of antibiotic treatment in cases that include signs of heart failure, large vegetations with high risk of embolic events, or infections refractory to antibiotic therapy ${ }^{39}$ (Figure 2). A recent meta-analysis confirmed that early surgery was associated with lower inhospital and long-term mortality compared with postponed surgical treatment, particularly in NVE. ${ }^{40}$ The optimal timing for surgery in the case of cerebral events has been discussed in the 2009 European Society of Cardiology (ESC) guidelines. ${ }^{20}$ In cases of stroke, after exclusion of coma and cerebral hemorrhage, surgery should not be postponed (class IIa, level B). In cases of minor cerebral events, such as transient ischemic attach or silent cerebral embolism, surgery is recommended without delay (class 1, level B). In the presence of intracranial hemorrhage, delaying surgery for at least 1 month is recommended (class 1 , level C). ${ }^{20}$ More recently, Okita et al. ${ }^{41}$ in a large retrospective cohort confirmed the safety of early surgery $(<7$ days) only in cases of nonhemorrhagic stroke. A repeated computed tomographic scan immediately before surgery to exclude a preoperative hemorrhagic transformation of a brain infarction or the development of mycotic aneurysm is mandatory. ${ }^{42}$

\section{HOW TO TREAT? A SYSTEMATIC APPROACH Localized Infection: Conservative Surgery}

The aim of surgery is to restore competence of the mitral valve and to avoid the risk of bacterial embolism during removal of the infection (Video 1 ). ${ }^{43}$ If only one leaflet or scallop is involved, conservative surgery is possible (Figures 2, 3, 4, C, 4, D, and Videos 2, 3). The goals of mitral valve repair are to remove vegetation while restoring a proper line of coaptation on both leaflets, to repair the leaflet if perforated, and to preserve the subvalvular apparatus. Excision of the vegetation-namely vegetectomy-can be performed along its cleavage plane on the leaflet. Generally, the reinforcement of leaflets with a pericardial patch is preferred over direct suture of the lesion, because this avoids tension on the suture line. The feasibility of valve repair depends on the extent of tissue destruction. Patients with limited active infection without valve destruction are the best candidates. Extensive damage of the anterior leaflet large lesions involving the posterior leaflet or the mitral valve commissures and annular abscesses are considered the main obstacles to mitral repair. ${ }^{44-47}$

Specifically, when the vegetation (Figure 4) is located on P3 and on the posteromedial commissure with no further involvement of the A2 or A3 scallops, reconstruction after excision of the infected segment can be performed using

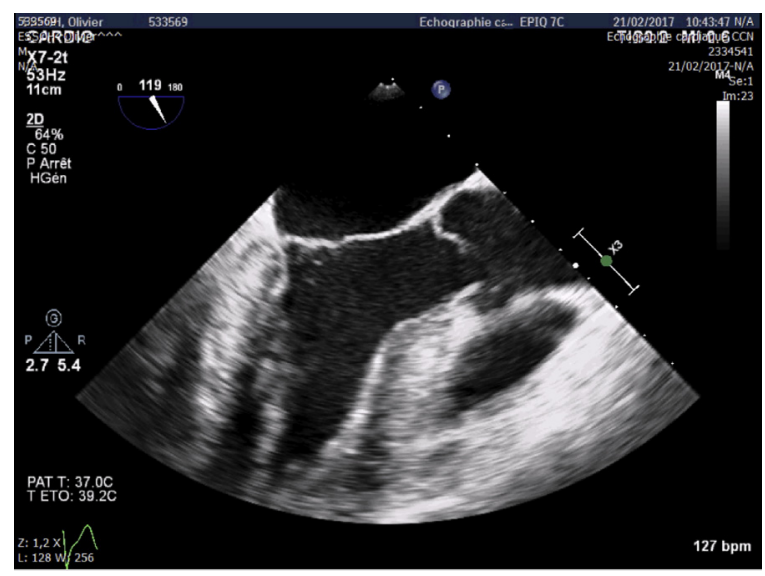

VIDEO 1. Transesophageal echocardiography of normal mitral valve. Video available at: https://www.jtcvs.org/article/S0022-5223(18)30982-6/ fulltext. 


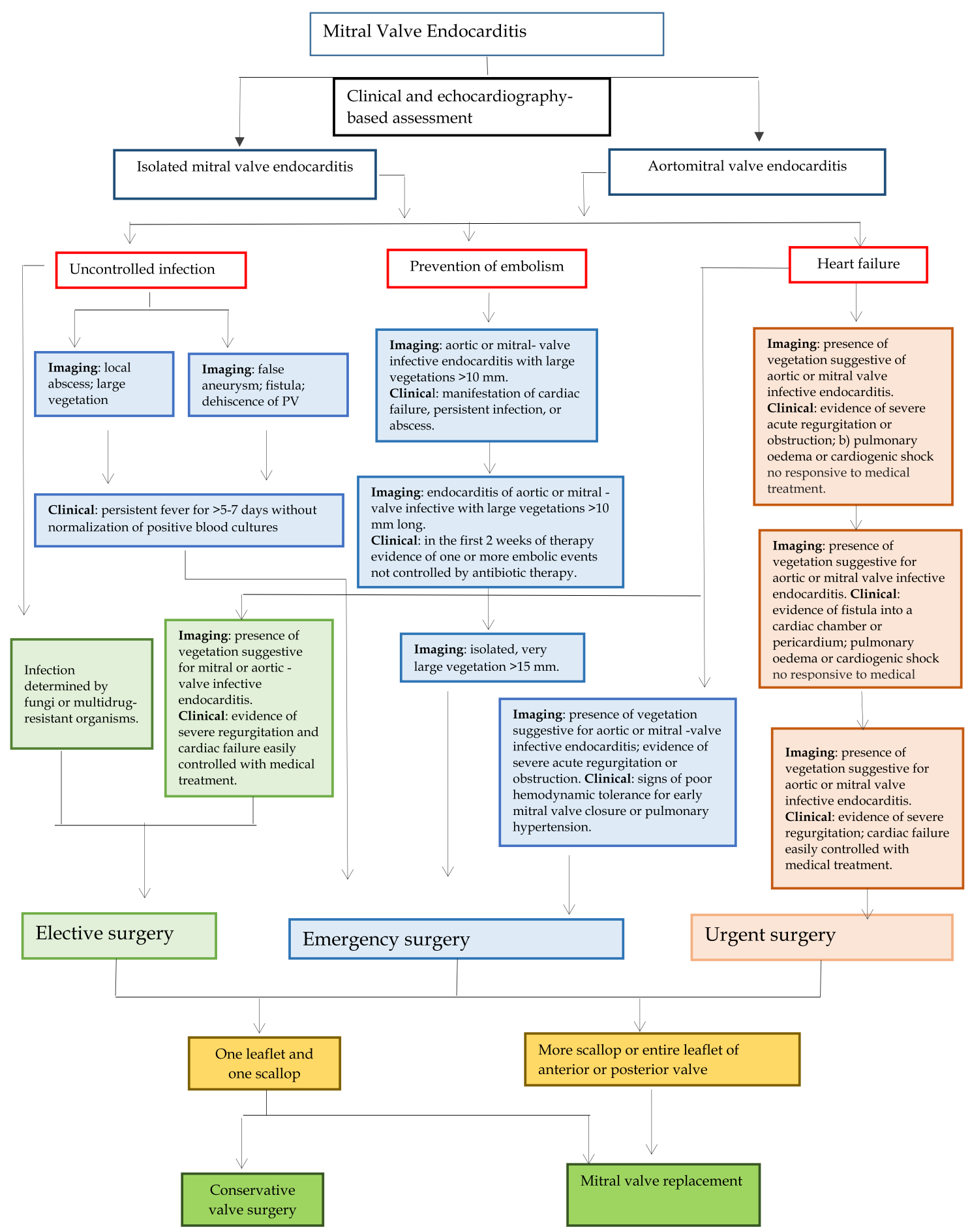

FIGURE 2. Indications for surgery of isolated or complex mitral valve endocarditis. The 2011, 2016, and 2017 Society of Thoracic Surgeons-American Association for Thoracic Surgery guidelines for the treatment of patients with valvular heart infective disease are summarized. Three different pathways (light green, light pink, and light blue boxes) according to the degree of urgency are depicted, describing the clinical presentation (red boxes) and imaging findings. Decisional algorithm for elective, urgent, or emergency surgery are shown in light green, light pink, or light blue boxes in the flow chart, respectively. Choice of surgical strategy (ie, repair or replacement) is based on the clinical and anatomic findings on preoperative imaging. If the infection process is limited to a localized area of the valve leaflets, mitral valve repair should be considered. In cases of extensive anatomic involvement of the valve, surgical mitral valve replacement is recommended. Timing of surgery should be the result of a shared multidisciplinary decision. In emergency surgery, treatment of the infected valve is required within 24 hours after completion of the diagnostic workup. Patients whose condition is urgent should undergo surgery within a few days upon indication. Elective surgery should be performed after at least 1 to 2 weeks of antibiotic therapy. PV, Prosthetic valve. 


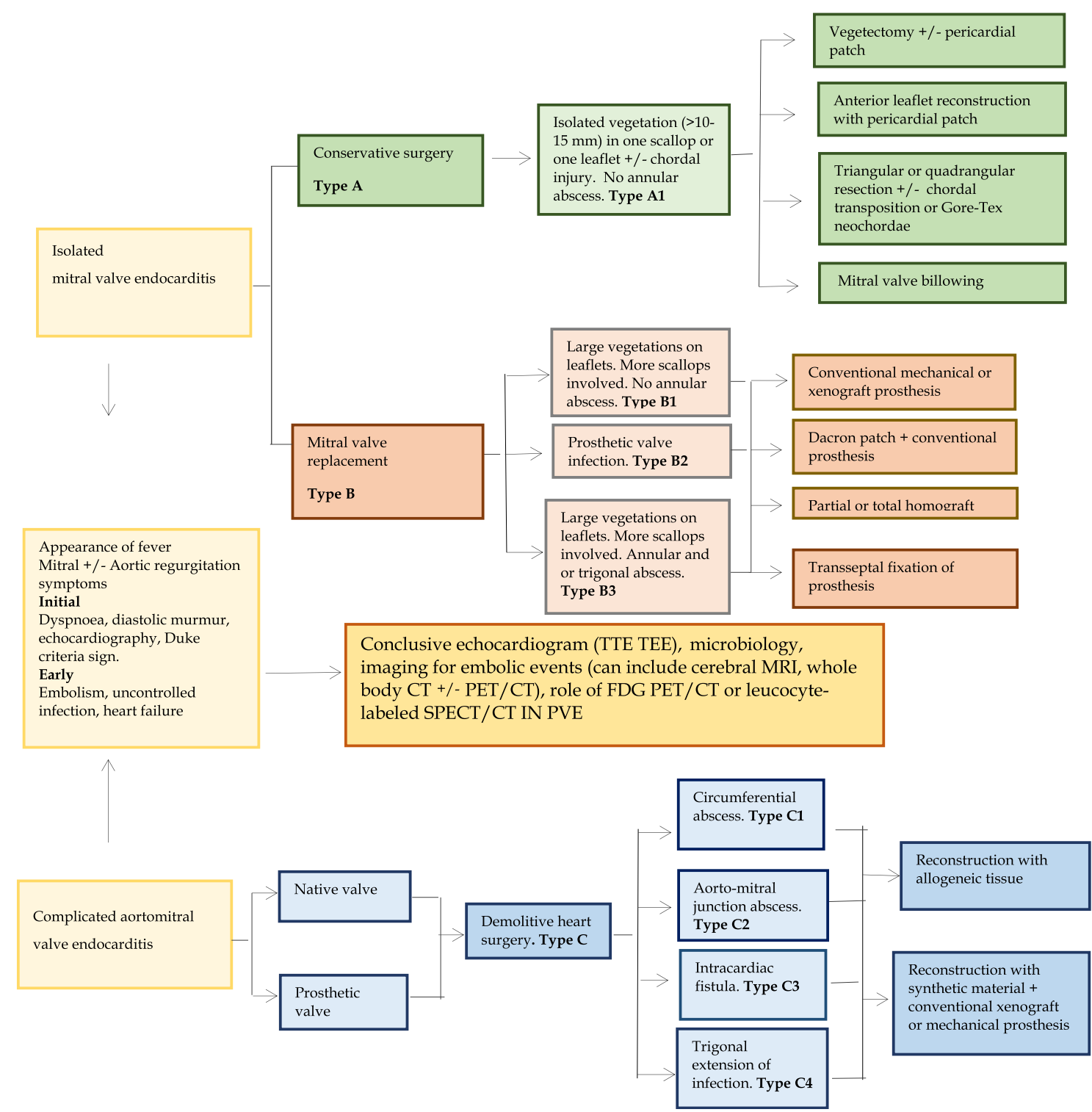

FIGURE 3. Diagnostic approach to the treatment of suspected mitral valve endocarditis. An algorithm for the surgical treatment of patients with suspected mitral valve endocarditis is depicted. The classic triad of symptoms of mitral valve $(M V)$ endocarditis—fever, dyspnea, and embolism—occurs at an early stage of the disease. Echocardiography is appropriate to evaluate MV endocarditis in any patient with a murmur and symptoms that might be related to mitral valve regurgitation. Transesophageal echocardiography (TEE) has higher specificity and is required in case of a high suspicion of infection despite the results of transthoracic echocardiography being negative. Microbiology, imaging for embolic events (can include cerebral magnetic resonance imaging [MRI], whole-body computed tomography $[C T]$ with or without positron emission tomography $[P E T]-\mathrm{CT}$, fluorodeoxyglucose $[F D G]$ PET-CT, or leucocytelabeled single photon emission CT [SPECT]) has an important role, especially in prosthetic valve endocarditis. A systematic approach in relation to the extension of disease is proposed. The severity of MV endocarditis can be categorized into 3 types according echocardiographic findings. In type A, mitral valve repair is suitable. In type B, valve replacement is most appropriate. In type C, with complicated mitral-aortic endocarditis (native or prosthetic) and potential for demolitive heart surgery, combined echocardiographic and CT with or without PET/CT should be obtained, especially if a patient presents with an embolic event. Multidisciplinary decision making is useful to avoid overestimation or underestimation of endocarditis severity. In case of overestimation with scarcely symptomatic patients, other potential causes of the clinical manifestations should be ruled out or treated before extensive and aggressive surgery is considered. Some patients can have a functioning prosthesis, without large vegetation, but abscess cavity or fistulas in surrounding parts of the heart might still be present. (From Aubert and colleagues.)

tissue from a billowing A2 medial or A3 segment. ${ }^{48}$ Otherwise, in patients with isolated vegetation of the posterior scallop P1, repair is possible with a limited resection of this scallop. A safer repair may be achieved by excision of the infected segment and a limited number of adjacent chordae followed by chordal transposition from P2 to P1 and 


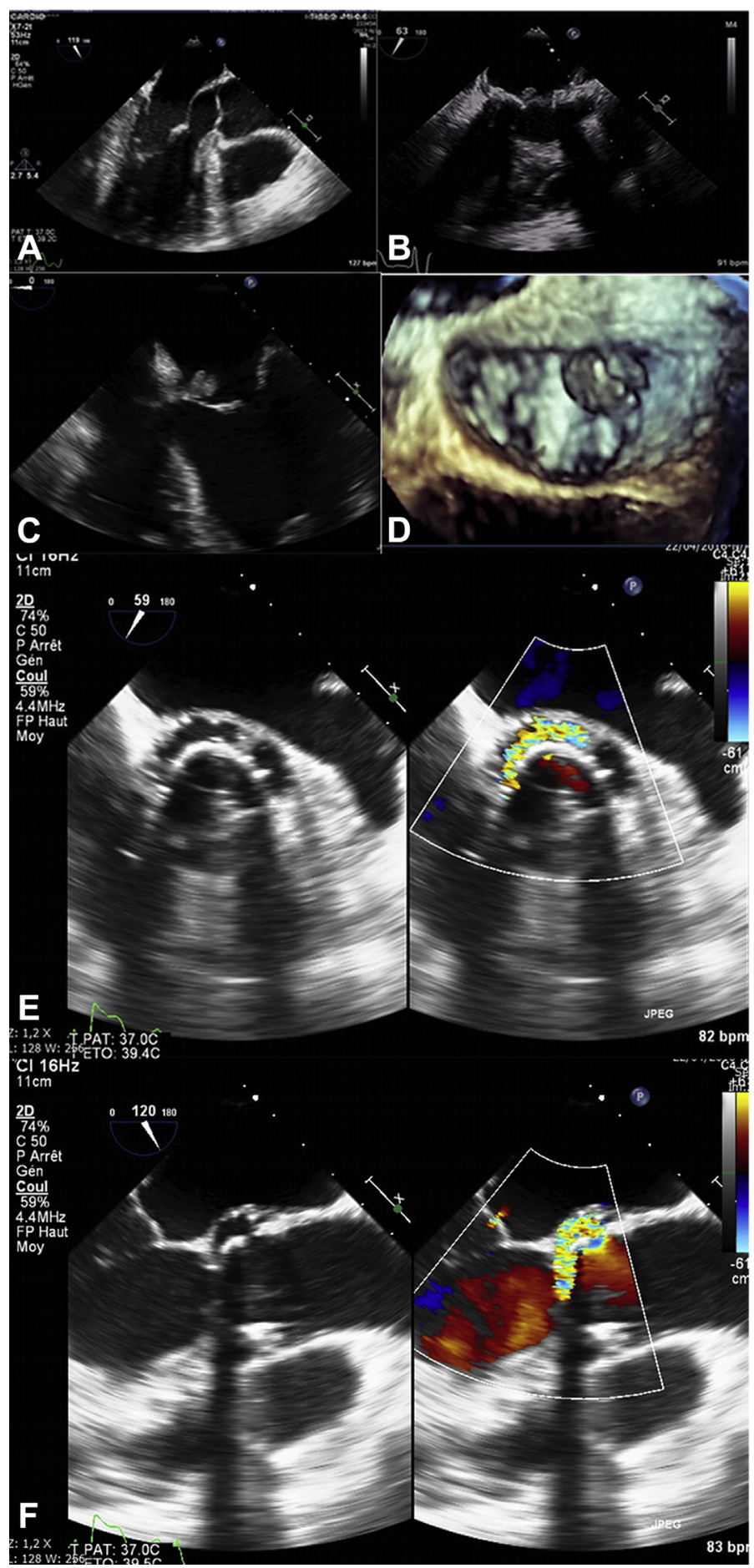

FIGURE 4. Echocardiographic findings in mitral valve endocarditis. A, Normal mitral valve in two-dimensional transesophageal echocardiography (2D TEE) with the probe rotated to $120^{\circ}$. The thin valve leaflets are visualized in the open position, in mid-diastole, while the aortic valve is closed. The left atrium is not enlarged, and the left ventricle is normal in terms of size and wall thickness. B, Mitral xenograft endocarditis. C, 2D TEE displaying a vegetation on the atrial aspect of the anterior leaflet (also see Video 2). D, Three-dimensional reconstruction of the mitral valve (surgeon's view) depicting the vegetation in C (also see Video 3). Prosthetic valve endocarditis is present. Short-axis (probe angle $59^{\circ}$ ) (E) and long-axis (probe angle $120^{\circ}$ ) $(\mathrm{F})$ view with and without color-Doppler analysis of a mechanical aortic prosthesis with a posterior semilunar abscess involving the aortomitral junction. 


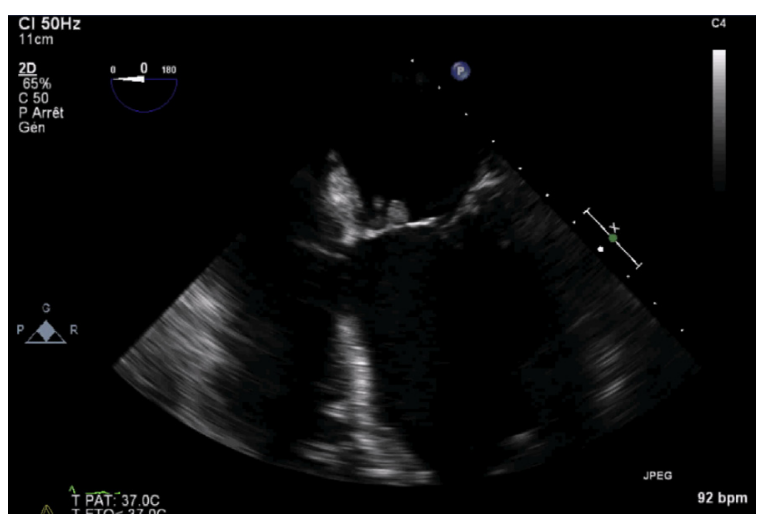

VIDEO 2. Transesophageal echocardiography. Vegetation of the atrial aspect of the anterior leaflet. Video available at: https://www.jtcvs.org/ article/S0022-5223(18)30982-6/fulltext.

stabilization of the annulus with an annuloplasty ring ${ }^{49}$ (Figure 3, type A).

When infection is extended to the annulus at the level of P3 and posteromedial commissure with involvement of the chordae and the myocardium of the left ventricle, the use of autologous tissue of the tricuspid valve has been described. ${ }^{50}$ Annular abscess can degenerate in more aggressive lesions of the trigonal zones. Involvement of these structures or of the subvalvular apparatus with chordal damage determines valve function impairment with valve regurgitation.

\section{Extended Infection: Replacement Surgery}

In a systematic review of the literature evaluating the rate of morbidity and mortality of mitral valve repair compared with replacement in IE, the repair group showed a significantly lower in-hospital mortality $(2.3 \%$ vs $14.4 \%$ ) and a significantly better 10-year survival rate compared with the replacement group (long-term mortality, $7.8 \%$ vs $40.5 \%){ }^{51}$ Similarly, another review of the literature showed better long-term event-free survival. ${ }^{52}$

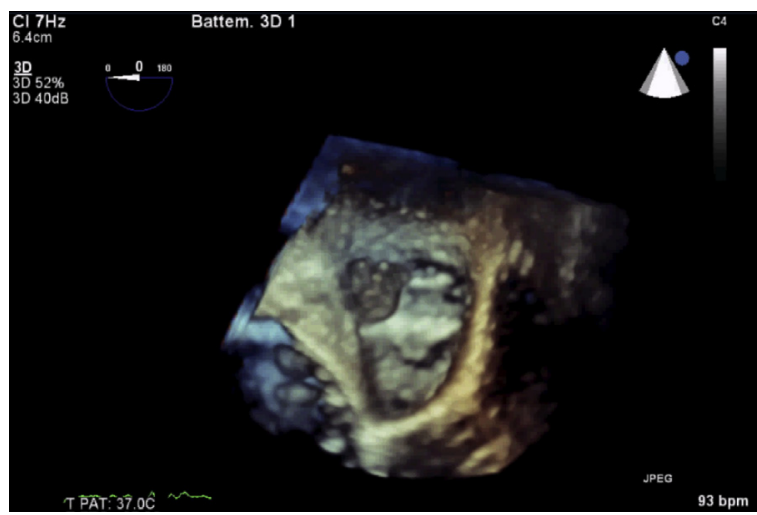

VIDEO 3. Transesophageal echocardiography. Three-dimensional reconstruction of vegetation of the anterior leaflet. Video available at: https://www.jtcvs.org/article/S0022-5223(18)30982-6/fulltext.

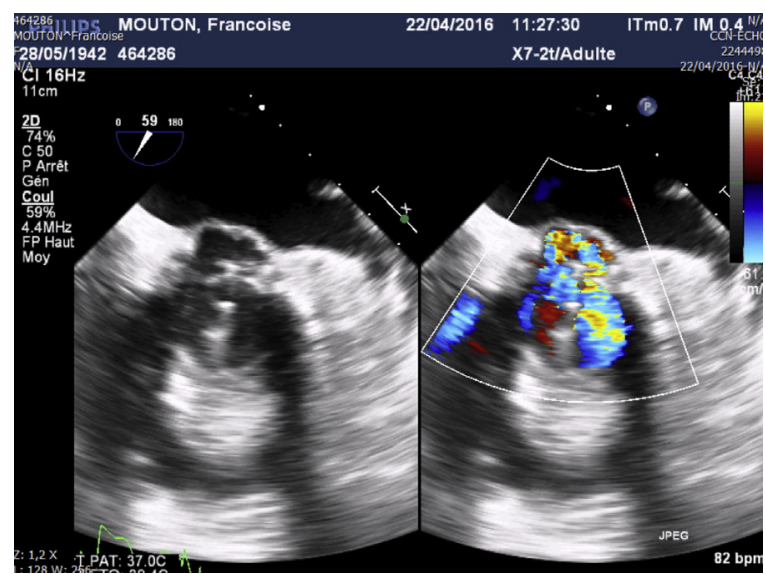

VIDEO 4. Transesophageal echocardiography. Prosthetic aortic mechanical valve endocarditis with a semilunar abscess involving the aorto-mitral junction. Video available at: https://www.jtcvs.org/article/S0022-5223(18) 30982-6/fulltext.

In addition, a recent systematic analysis showed a trend toward the superiority of valve repair over replacement in terms of recurrence of endocarditis. ${ }^{52}$ Although the guidelines recommend mitral valve repair over replacement whenever possible, ${ }^{3,18,53}$ as recently discussed, the possibility of repair is dependent on the preoperative conditions and intraoperative findings. ${ }^{54,55}$ Clearly, in cases of extended infection on more than one leaflet with or without annular abscess or in cases of PVE (Figures $4 B, E$, and $F$, and Video 4). mitral replacement should be the preferred approach (Figure 3, type B). Mitral valve replacement can be performed with the use of either biological derivates (ie, allogeneic tissue or stented xenografts) or mechanical prosthesis. However, there are several disadvantages to mitral valve replacement. For mechanical valves, the need for lifelong anticoagulation and the risk of thromboembolism are the main drawbacks; conversely, structural valve deterioration (SVD) and failure hinder the use of stented xenografts and cryopreserved mitral allografts. Greason et al. ${ }^{56}$ showed no significant difference in overall mortality and recurrence of infection in a large 35-year follow-up when comparing mechanical valves versus bioprostheses. ${ }^{56}$ Musci et al. ${ }^{57}$ in a 22 -year experience demonstrated a trend toward increased risk of infection in the bioprostheses. ${ }^{57}$ Similarly, the Stanford group identified lower freedom from reoperation in the bioprosthetic group $^{58}$; therefore, the general tendency is to recommend mechanical valve replacement to most patients younger than 60 years. ${ }^{56}$ Importantly, if the chordae tendineae are cut off during replacement, the ventricular wall is no longer anchored to the valve apparatus; this results in the loss of the chordae physiologic tethering effect, with significant effects on the long-term outcomes, particularly in younger patients. Moreover, left ventricular wall stress might increase, and left ventricular function can 


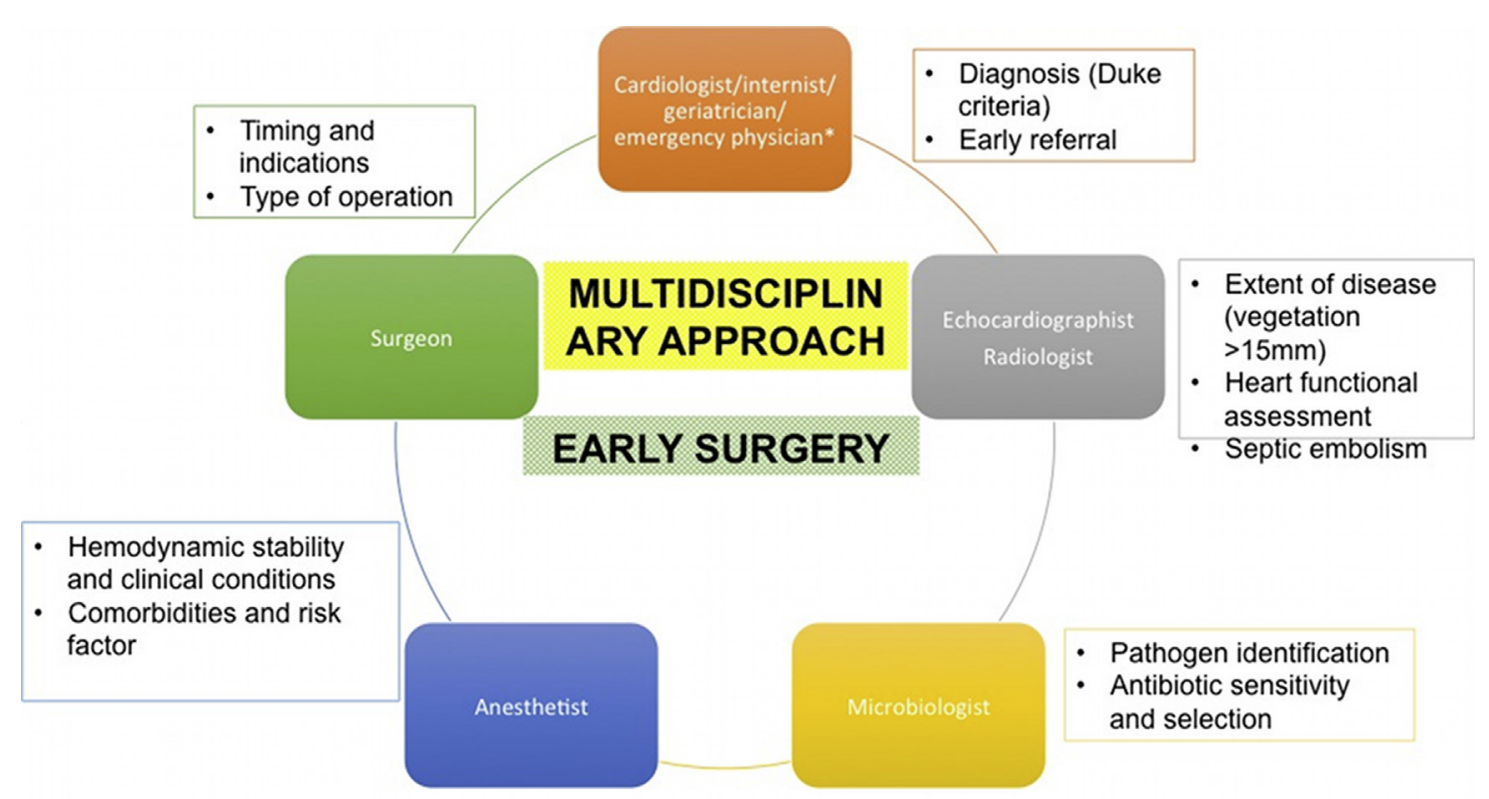

FIGURE 5. Clinical perspective and take-home messages regarding this review, highlighting the main novelties proposed in the management of mitral valve endocarditis: a coordinated multidisciplinary effort in the diagnostic work-up and the need for early surgical referral, especially in conditions of high risk of embolization, and clinical deterioration with signs of heart failure notwithstanding the establishment of the appropriate antibiotic therapy. Mitral valve endocarditis is a complex disease, and it should be addressed by means of a multidisciplinary approach involving different professionals contributing their expertise to the decision making. A diagram is proposed in which the single professional roles are highlighted. The coordinated efforts of the team members should converge toward early referral of the patient to specialized centers with the goal of performing surgery at an early stage according to patient conditions. Temporizing on the surgical decision should be avoided, especially in complex and extensive endocarditis in which radical and demolitive surgical approaches involving the use of homografts or xenografts are encouraged. The relative specialist will be involved according to the individual characteristics, needs or comorbidities of the single patient.

deteriorate with early onset of heart failure. Despite the recent questions by Kim et al, ${ }^{59}$ the use of homografts in nonextensive endocarditis has been supported by several authors. ${ }^{46,55,60-64}$

\section{Complicated Aorto-Mitral Endocarditis: Demolitive Surgery}

Patients with staphylococcus-positive culture results have an increased risk of developing complex and aggressive lesions, such as mitral annulus and aortic root abscess formation. These patients also have a significantly higher mortality compared with infection sustained by other pathogens. Aortomitral junction extension, circumferential annular abscess, or the development of intracardiac fistulae require extensive demolition and debridement of the infected tissue and subsequent reconstruction with allogeneic tissues (Figure 3, type $C$ ). In our group both total and partial homografts have been used with encouraging results. ${ }^{46,47,61,65}$ Freedom from SVD was $90 \%, 76 \%$, and $65 \%$ at 5,10 , and 15 years, respectively; freedom from reoperation was $88 \%, 80 \%$, and $64 \%$ at 5,10 , and 15 years, respectively. ${ }^{65}$ Patients with total homografts were more prone to the occurrence of SVD as mixed stenosis and insufficiency. SVD was more prevalent in cases of non-endocarditis etiology and in patients who had experienced pregnancy. ${ }^{62,65}$
Similar results were echoed in a mitral homograft series from Yankah et al. ${ }^{64}$ and another study reporting the use of mitral homograft in the tricuspid position by Mestres et al. ${ }^{66}$

The comparability of mitral homograft with bioprostheses reported in a cohort of young patients, ${ }^{60}$ together with the ease of use of these biosubstitutes in young females planning future pregnancies, ${ }^{67,68}$ are strong points in favor of homografts in this context.

For cases of aortomitral curtain and aortic root involvement, the use of a monobloc aortomitral homograft has been described by Obadia et al. ${ }^{69}$ Our group used a double homograft replacement as a separate bloc with a partial or total mitral homograft because we believed this would reduce the risk of size mismatch compared with the monobloc technique and would prevent the need for reconstruction of the left atrial roof. ${ }^{70}$

Per the results of our 8-year follow-up study, the addition of a prosthetic ring in the mitral homograft is advised to improve the durability of the mitral replacement. ${ }^{60}$ In terms of the implant technique, intraventricular fixation in a sideto-side position on the recipient papillary muscle produced satisfactory outcomes, even in cases of largely infected and fragile mitral tissues. ${ }^{47,61} \mathrm{We}$ found that this technique could reduce the risk of the papillary muscle rupture reported in other series. ${ }^{63,64}$ 


\section{CONCLUSIONS}

Surgery for MVE begins with a comprehensive clinical evaluation and systematic assessment of the characteristics of the lesions. Several clinical and anatomopathological variables are known to affect postoperative survival. Indications and timing for surgery are centered on the need to restore mitral function rapidly, reduce the risk of embolization (ie, vegetation larger than $15 \mathrm{~mm}$ ), and avoid deterioration with precipitating heart failure (Figure E1). Therefore, hemodynamic instability, elevated risk of embolization with extensive valvular lesions, and inability to control the infection notwithstanding appropriate antibiotic treatment might be considered compelling factors in favor of an emergent operation, outweighing the risk of the procedure itself. Variables influencing the decision on the type of operation to be performed include the etiology (ie, noninvasive or invasive organism), extent of the infective lesion, involvement of a native or a prosthetic valve, and patient age and comorbidities, including the presence of cardiac or extracardiac organ dysfunction.

Patients with a single infected scallop that does not involve the entire anterior or posterior leaflet have survival benefit from mitral valve repair and should generally receive vegetectomy or reconstruction of the perforated mitral segment with a pericardial patch. In cases involving 2 or 3 scallops with left ventricular dysfunction or renal or other extra-cardiac organ failure, valve repair is not recommended, and replacement with either prosthetic or allogeneic tissues is preferred. Evidence of complex endocarditis with involvement of the mitral annulus, abscess of the mitral-aortic junction, and the presence of fistula requires extensive surgery with the aid of homografts and synthetic material (Figure 5).

\section{Conflict of Interest Statement}

Authors have nothing to disclose with regard to commercial support.

\section{References}

1. Cresti A, Chiavarelli M, Scalese M, Nencioni C, Valentini S, Guerrini F, et al. Epidemiological and mortality trends in infective endocarditis, a 17-year population-based prospective study. Cardiovasc Diagn Ther. 2017;7:27-35.

2. Correa de Sa DD, Tleyjeh IM, Anavekar NS, Schultz JC, Thomas JM, Lahr BD, et al. Epidemiological trends of infective endocarditis: a population-based study in Olmsted County, Minnesota. Mayo Clin Proc. 2010;85:422-6.

3. Nishimura RA, Otto CM, Bonow RO, Carabello BA, Erwin JP 3rd, Guyton RA, et al. 2014 AHA/ACC guideline for the management of patients with valvular heart disease: a report of the American College of Cardiology/American Heart Association Task Force on Practice Guidelines. J Thorac Cardiovasc Surg. 2014;148:e1-132.

4. David TE, Gavra G, Feindel CM, Regesta T, Armstrong S, Maganti MD. Surgical treatment of active infective endocarditis: a continued challenge. J Thorac Cardiovasc Surg. 2007; 133:144-9.

5. Prendergast BD. The changing face of infective endocarditis. Heart. 2006;92: 879-85.

6. Curlier E, Hoen B, Alla F, Selton-Suty C, Schubel L, Doco-Lecompte T, et al. Relationships between sex, early valve surgery and mortality in patients with left-sided infective endocarditis analysed in a population-based cohort study. Heart. 2014;100:1173-8.

7. Duval X, Delahaye F, Alla F, Tattevin P, Obadia JF, Le Moing V, et al. Temporal trends in infective endocarditis in the context of prophylaxis guideline modifications: three successive population-based surveys. J Am Coll Cardiol. 2012;59:1968-76.

8. Sy RW, Kritharides L. Health care exposure and age in infective endocarditis: results of a contemporary population-based profile of 1536 patients in Australia. Eur Heart J. 2010;31:1890-7.

9. Fedeli U, Schievano E, Buonfrate D, Pellizzer G, Spolaore P. Increasing incidence and mortality of infective endocarditis: a population-based study through a record-linkage system. BMC Infect Dis. 2011;11:48.

10. Murdoch DR, Corey GR, Hoen B, Miro JM, Fowler VG Jr, Bayer AS, et al. Clinical presentation, etiology, and outcome of infective endocarditis in the 21 st century: the International Collaboration on Endocarditis-Prospective Cohort Study Arch Intern Med. 2009;169:463-73.

11. Di Salvo G, Habib G, Pergola V, Avierinos JF, Philip E, Casalta JP, et al. Echocardiography predicts embolic events in infective endocarditis. J Am Coll Cardiol. 2001;37:1069-76.

12. Federspiel JJ, Stearns SC, Peppercorn AF, Chu VH, Fowler VG Jr. Increasing US rates of endocarditis with Staphylococcus aureus: 1999-2008. Arch Intern Med. 2012;172:363-5.

13. Tleyjeh IM, Abdel-Latif A, Rahbi H, Scott CG, Bailey KR, Steckelberg JM, et al. A systematic review of population-based studies of infective endocarditis. Chest. 2007; 132:1025-35.

14. Selton-Suty C, Celard M, Le Moing V, Doco-Lecompte T, Chirouze C, Iung B, et al. Preeminence of Staphylococcus aureus in infective endocarditis: a 1-year population-based survey. Clin Infect Dis. 2012;54:1230-9.

15. Desimone DC, Tleyjeh IM, Correa de Sa DD, Anavekar NS, Lahr BD, Sohail MR, et al. Incidence of infective endocarditis caused by viridans group streptococci before and after publication of the 2007 American Heart Association's endocarditis prevention guidelines. Circulation. 2012; 126:60-4.

16. Crawford MH, Durack DT. Clinical presentation of infective endocarditis. Cardiol Clin. 2003;21:159-66.v.

17. Li JS, Sexton DJ, Mick N, Nettles R, Fowler VG Jr, Ryan T, et al. Proposed modifications to the Duke criteria for the diagnosis of infective endocarditis. Clin Infect Dis. 2000;30:633-8.

18. Nishimura RA, Otto CM, Bonow RO, Carabello BA, Erwin JP 3rd, Fleisher LA, et al. 2017 AHA/ACC Focused Update of the 2014 AHA/ACC Guideline for the Management of Patients With Valvular Heart Disease: A Report of the American College of Cardiology/American Heart Association Task Force on Clinical Practice Guidelines. Circulation. 2017;135:e1159-95.

19. Gould FK, Denning DW, Elliott TS, Foweraker J, Perry JD, Prendergast BD, et al. Guidelines for the diagnosis and antibiotic treatment of endocarditis in adults: a report of the Working Party of the British Society for Antimicrobial Chemotherapy. J Antimicrob Chemother. 2012;67:269-89.

20. Habib G, Hoen B, Tornos P, Thuny F, Prendergast B, Vilacosta I, et al. Guidelines on the prevention, diagnosis, and treatment of infective endocarditis (new version 2009): the Task Force on the Prevention, Diagnosis, and Treatment of Infective Endocarditis of the European Society of Cardiology (ESC). Endorsed by the European Society of Clinical Microbiology and Infectious Diseases (ESCMID) and the International Society of Chemotherapy (ISC) for Infection and Cancer. Eur Heart J. 2009;30:2369-413.

21. Baddour LM, Wilson WR, Bayer AS, Fowler VG Jr, Bolger AF, Levison ME, et al. Infective endocarditis: diagnosis, antimicrobial therapy, and management of complications: a statement for healthcare professionals from the Committee on Rheumatic Fever, Endocarditis, and Kawasaki Disease, Council on Cardiovascular Disease in the Young, and the Councils on Clinical Cardiology, Stroke, and Cardiovascular Surgery and Anesthesia, American Heart Association: endorsed by the Infectious Diseases Society of America. Circulation. 2005;111:e394-434.

22. Isaksson J, Rasmussen M, Nilson B, Stadler LS, Kurland S, Olaison L, et al. Comparison of species identification of endocarditis associated viridans streptococci using rnpB genotyping and 2 MALDI-TOF systems. Diagn Microbiol Infect Dis. 2015;81:240-5.

23. Fournier PE, Thuny F, Richet H, Lepidi H, Casalta JP, Arzouni JP, et al. Comprehensive diagnostic strategy for blood culture-negative endocarditis: a prospective study of 819 new cases. Clin Infect Dis. 2010;51:131-40.

24. Lepidi H, Coulibaly B, Casalta JP, Raoult D. Autoimmunohistochemistry: a new method for the histologic diagnosis of infective endocarditis. J Infect Dis. 2006; 193:1711-7. 
25. Greub G, Lepidi H, Rovery C, Casalta JP, Habib G, Collard F, et al. Diagnosis of infectious endocarditis in patients undergoing valve surgery. Am J Med. 2005; 118:230-8.

26. Thuny F, Di Salvo G, Belliard O, Avierinos JF, Pergola V, Rosenberg V, et al. Risk of embolism and death in infective endocarditis: prognostic value of echocardiography: a prospective multicenter study. Circulation. 2005;112:69-75.

27. Thuny F, Avierinos JF, Tribouilloy C, Giorgi R, Casalta JP, Milandre L, et al. Impact of cerebrovascular complications on mortality and neurologic outcome during infective endocarditis: a prospective multicentre study. Eur Heart J. 2007:28:1155-61.

28. Sonneville R, Mirabel M, Hajage D, Tubach F, Vignon P, Perez P, et al. Neurologic complications and outcomes of infective endocarditis in critically ill patients: the ENDOcardite en REAnimation prospective multicenter study. Crit Care Med. 2011;39:1474-81.

29. Duval X, Iung B, Klein I, Brochet E, Thabut G, Arnoult F, et al. Effect of early cerebral magnetic resonance imaging on clinical decisions in infective endocarditis: a prospective study. Ann Intern Med. 2010;152:497-504. W175.

30. Dickerman SA, Abrutyn E, Barsic B, Bouza E, Cecchi E, Moreno A, et al. The relationship between the initiation of antimicrobial therapy and the incidence of stroke in infective endocarditis: an analysis from the ICE Prospective Cohort Study (ICE-PCS). Am Heart J. 2007;154:1086-94.

31. Lalani T, Chu VH, Park LP, Cecchi E, Corey GR, Durante-Mangoni E, et al. Inhospital and 1-year mortality in patients undergoing early surgery for prosthetic valve endocarditis. JAMA Intern Med. 2013;173:1495-504.

32. Thuny F, Beurtheret S, Mancini J, Gariboldi V, Casalta JP, Riberi A, et al. The timing of surgery influences mortality and morbidity in adults with severe complicated infective endocarditis: a propensity analysis. Eur Heart J. 2011; 32:2027-33.

33. Botelho-Nevers E, Thuny F, Casalta JP, Richet H, Gouriet F, Collart F, et al. Dramatic reduction in infective endocarditis-related mortality with a managementbased approach. Arch Intern Med. 2009;169:1290-8.

34. Peters PJ, Harrison T, Lennox JL. A dangerous dilemma: management of infectious intracranial aneurysms complicating endocarditis. Lancet Infect Dis. 2006; 6:742-8.

35. Toyoda N, Itagaki S, Egorova NN, Tannous H, Anyanwu AC, El-Eshmawi A, et al. Real-world outcomes of surgery for native mitral valve endocarditis. $J$ Thorac Cardiovasc Surg. 2017.

36. Manne MB, Shrestha NK, Lytle BW, Nowicki ER, Blackstone E, Gordon SM, et al. Outcomes after surgical treatment of native and prosthetic valve infective endocarditis. Ann Thorac Surg. 2012;93:489-93.

37. Kang DH, Kim YJ, Kim SH, Sun BJ, Kim DH, Yun SC, et al. Early surgery versus conventional treatment for infective endocarditis. N Engl J Med. 2012;366: 2466-73.

38. Kang DH, Lee S, Kim YJ, Kim SH, Kim DH, Yun SC, et al. Long-Term Results of Early Surgery versus Conventional Treatment for Infective Endocarditis Trial. Korean Circ J. 2016;46:846-50.

39. Nappi F, Spadaccio C. Keep fumbling around in the dark when it comes to infective endocarditis, or produce new, reliable data to redesign the guidelines? J Thorac Cardiovasc Surg. 2018;155:75-6.

40. Liang F, Song B, Liu R, Yang L, Tang H, Li Y. Optimal timing for early surgery in infective endocarditis: a meta-analysis. Interact Cardiovasc Thorac Surg. 2016; 22:336-45.

41. Okita Y, Minakata K, Yasuno S, Uozumi R, Sato T, Ueshima K, et al. Optimal timing of surgery for active infective endocarditis with cerebral complications: a Japanese multicentre study. Eur J Cardiothorac Surg. 2016;50:374-82.

42. Rossi M, Gallo A, De Silva RJ, Sayeed R. What is the optimal timing for surgery in infective endocarditis with cerebrovascular complications? Interact Cardiovasc Thorac Surg. 2012;14:72-80.

43. Byrne JG, Rezai K, Sanchez JA, Bernstein RA, Okum E, Leacche M, et al. Surgical management of endocarditis: the society of thoracic surgeons clinical practice guideline. Ann Thorac Surg. 2011;91:2012-9.

44. Hussain ST, Shrestha NK, Gordon SM, Houghtaling PL, Blackstone EH, Pettersson GB. Residual patient, anatomic, and surgical obstacles in treating active left-sided infective endocarditis. J Thorac Cardiovasc Surg. 2014;148:981-8.e4.

45. Nappi F, Spadaccio C, Acar C. Use of allogeneic tissue to treat infective valvular disease: Has everything been said? J Thorac Cardiovasc Surg. 2017;153:824-8.

46. Acar C, Farge A, Ramsheyi A, Chachques JC, Mihaileanu S, Gouezo R, et al. Mitral valve replacement using a cryopreserved mitral homograft. Ann Thorac Surg. 1994;57:746-8.

47. Acar C, Tolan M, Berrebi A, Gaer J, Gouezo R, Marchix T, et al. Homograft replacement of the mitral valve. Graft selection, technique of implantation, and results in forty-three patients. J Thorac Cardiovasc Surg. 1996;111:367-78; discussion $78-80$.

48. Miura T, Nakaji S, Ariyoshi T, Tsuneto A, Hashizume K, Eishi K. Mitral leafle restoration using a billowing leaflet in active infective endocarditis. Ann Thorac Surg. 2014;97:e47-8.

49. Ruggieri VG, Paramythiotis A, Corbineau H, Leguerrier A. Posterior leaflet P2 P1 transposition for mitral repair in a case of infective endocarditis. J Heart Valve Dis. 2013;22:39-41.

50. de Kerchove L, Vanoverschelde JL, Poncelet A, Glineur D, Rubay J, Zech F, et al Reconstructive surgery in active mitral valve endocarditis: feasibility, safety and durability. Eur J Cardiothorac Surg. 2007;31:592-9.

51. Feringa HH, Shaw LJ, Poldermans D, Hoeks S, van der Wall EE, Dion RA, et al Mitral valve repair and replacement in endocarditis: a systematic review of literature. Ann Thorac Surg. 2007;83:564-70.

52. Zhao D, Zhang B. Are valve repairs associated with better outcomes than replacements in patients with native active valve endocarditis? Interact Cardiovasc Thorac Surg. 2014;19:1036-9.

53. Chairs ASToIECGWC, Pettersson GB, Coselli JS, Writing C, Hussain ST, Griffin B, et al. 2016 The American Association for Thoracic Surgery (AATS) consensus guidelines: Surgical treatment of infective endocarditis: Executive summary. J Thorac Cardiovasc Surg. 2017;153: 1241-58.e29.

54. Bando K. Does type of prosthesis affect long-term outcomes after aortic valve replacement for infective endocarditis? How should we properly answer this question? J Thorac Cardiovasc Surg. 2017;153:829-30.

55. Nappi F, Spadaccio C. Simplest solutions are not always the cleverest: Can we stitch in an infected annulus? Should we rethink the current guidelines? J Thorac Cardiovasc Surg. 2017;154:1899-900.

56. Greason KL, Thomas M, Steckelberg JM, Daly RC, Schaff HV, Li Z, et al. Outcomes of surgery in the treatment of isolated nonnative mitral valve infective endocarditis. J Thorac Cardiovasc Surg. 2014;147:349-54.

57. Musci M, Hubler M, Amiri A, Stein J, Kosky S, Meyer R, et al. Surgical treatmen for active infective prosthetic valve endocarditis: 22-year single-centre experience. Eur J Cardiothorac Surg. 2010;38:528-38.

58. Moon MR, Miller DC, Moore KA, Oyer PE, Mitchell RS, Robbins RC, et al Treatment of endocarditis with valve replacement: the question of tissue versus mechanical prosthesis. Ann Thorac Surg. 2001;71:1164-71.

59. Kim JB, Ejiofor JI, Yammine M, Camuso JM, Walsh CW, Ando M, et al. Are homografts superior to conventional prosthetic valves in the setting of infective endocarditis involving the aortic valve? J Thorac Cardiovasc Surg. 2016;151: 1239-46, e1-2.

60. Ali M, Iung B, Lansac E, Bruneval P, Acar C. Homograft replacement of the mitral valve: eight-year results. J Thorac Cardiovasc Surg. 2004;128:529-34.

61. Doty DB, Acar C. Mitral valve replacement with homograft. Ann Thorac Surg 1998;66:2127-31.

62. Nappi F. The Cryopreserved Mitral Homograft Valve: 19 Years' Experience JACC Cardiovasc Interv. 2014;7:S58.

63. Kumar AS, Choudhary SK, Mathur A, Saxena A, Roy R, Chopra P. Homograft mitral valve replacement: five years' results. J Thorac Cardiovasc Surg. 2000; 120:450-8.

64. Yankah AC, Sievers HH, Lange PE, Bernhard A. Clinical report on stentless mitral allografts. J Heart Valve Dis. 1995;4:40-4.

65. Olivito S, Lalande S, Nappi F, Hammoudi N, D'Alessandro C, Fouret P, et al Structural deterioration of the cryopreserved mitral homograft valve. J Thorac Cardiovasc Surg. 2012;144:313-20.e1.

66. Mestres CA, Castella M, Moreno A, Pare JC, del Rio A, Azqueta M, et al. Cryopreserved mitral homograft in the tricuspid position for infective endocarditis: a valve that can be repaired in the long-term (13 years). J Heart Valve Dis. 2006;15: 389-91.

67. Sadler L, McCowan L, White H, Stewart A, Bracken M, North R. Pregnancy out comes and cardiac complications in women with mechanical, bioprosthetic and homograft valves. BJOG. 2000;107:245-53.

68. Nappi F, Spadaccio C, Chello M, Lusini M, Acar C. Impact of structural valve deterioration on outcomes in the cryopreserved mitral homograft valve. J Card Surg. 2014;29:616-22.

69. Obadia JF, Henaine R, Bergerot C, Ginon I, Nataf P, Chavanis N, et al. Monobloc aorto-mitral homograft or mechanical valve replacement: a new surgical option for extensive bivalvular endocarditis. J Thorac Cardiovasc Surg. 2006;131: 243-5.

70. Acar C. Monobloc or separate aortic and mitral homografts? J Thorac Cardiovasc Surg. 2006;132:442-3. author reply 3. 


\section{APPENDIX E1. CLINICAL PRESENTATION, MICROBIOLOGIC EVIDENCE, COMPLICATIONS, AND STRATEGY}

Evidence from an observational series on infective endocarditis (IE) suggests that the rate of mitral valve involvement is lower than that of the aortic valve. One study describing outcomes of 775 patients reported a prevalence of $51 \%$ for aortic valve involvement (among those, 59\% had prosthetic valve endocarditis [PVE] and $68 \%$ had invasive endocarditis) versus $30.7 \%$ for mitral valve involvement (PVE, 29\%; invasive endocarditis, 35\%). In another report, aortic valve involvement was $47 \%$, and mitral valve involvement was $31 \%$. In the French registry of the Association Pour l'Etude et la Prévention de l'Endocardite Infectieuse, the prevalence of IE ranges from $43.8 \%$ to $35.4 \%$. Active IE can involve a native valve (NVE) or a prosthetic valve (PVE), with a reported prevalence of around $50 \%$ for NVE and $10 \%$ for PVE. IE might present as affecting one isolated valve or involving other cardiac valves with varying degrees of extension to the cardiac structures. In some circumstances, aggressive infections can lead to extensive destructive damage of other valve components. In cases of extension to the aortomitral curtain or the involvement of more than one valve, reported in around $40 \%$ of cases, both preoperative and postoperative mortality increase significantly.

The natural history of mitral valve infection is heterogeneous and is significantly affected by the severity of mitral regurgitation, which is associated with the development of heart failure symptoms, pulmonary hypertension, and atrial fibrillation. Endocarditis of the mitral valve posteromedial papillary muscle can occur with variable degrees of chordal lesions; infective coronary and cerebrovascular embolism, stroke, and left ventricular rupture are other serious complications. In a large population-based study, the in-hospital mortality of mitral IE was $24 \%$ among surgically treated patients and $26.4 \%$ among medically treated patients, and it reached $29 \%$ after 1 year.

In addition, IE sustained by Staphylococcus aureus, normally resulting in extensive lesions, is associated with a significantly higher hospital mortality $(15 \%$ vs $8.4 \%)$, 6-month mortality $(23 \%$ vs $15 \%)$, and 1 -year mortality ( $28 \%$ vs $18 \%$ ) compared with non-S. aureus IE. For this reason, accurate diagnosis of infective mitral endocarditis requires identification of the causative microorganism.

In $80 \%$ of cases, mitral infective endocarditis is attributable to streptococci and staphylococci, although the proportions can vary considering the type of valve (native valve vs conventional stented xenograft or mechanical), the source of infection, patient age, and coexisting morbidities. Concerns regarding the prevalence of oral streptococci infection of the MV has decreased in industrialized countries (Figure 1). In $10 \%$ of cases when a blood culture result is negative, there are 2 possibilities: the patient is currently treated with an antibiotic that masks the microorganism or the infection is sustained by other microorganisms as Bartonella species, Brucella species, Coxiella burnetii, and a family of bacteria identified as the HACEK group (Haemophilus species Actinobacillus actinomycetemcomitans, Cardiobacterium hominis, Eikenella corrodens, and Kingella kingae). These microorganisms are detectable with serologic testing, such as valve or blood polymerase chain reaction assay, and highly specialized microbiologic techniques that allow for the identification of the pathogen in $60 \%$ of cases. Common serologic tests sometimes lack the sensitivity and specificity required for some strains of S. aureus and Streptococcus viridans that are known to be extremely aggressive. The latter is difficult to detect even with the use of sophisticated techniques, such as $\mathrm{mpB}$ genotyping and matrixassisted laser desorption/ionization time-of-flight systems (Figure 1). Persistent negative blood culture results can lead to a delay in treatment with significant effect on patient prognosis and should prompt emergency surgery if clinical conditions are deteriorating (see the algorithm in Figure 2).

The prolonged time required by the internists to achieve a diagnosis is often due to the difficulty in identifying the pathogen responsible. In the presence of aggressive and no detectable microorganisms, 24 to 48 hours of nontargeted antibiotic therapy can lead to extension of lesions with multiple valves involvement and destruction of large portions of the heart with consequent adverse outcomes. A typical example of this scenario is represented by IE sustained by intracellular microorganisms, such as C. burnetii, Bartonella species, or Tropheryma whipplei, in which the exposure and the status of the immune response of the host become decisive (Figure 1).

Mitral regurgitation characterizes the pathophysiology of MVE with progressive increase in mean left atrial pressure, left atrial enlargement with atrial fibrillation, left ventricle dysfunction, and further pulmonary congestion with pulmonary hypertension (Figure 1).

Embolization in the systemic circulation and particularly in the cerebral vessels is another major consequence (Figure E1). Cerebral events can complicate IE in 55\% of cases and in up to $36 \%$ of cases for MVE. Among those cases, ischemic and hemorrhagic stroke, transient ischemic attack, silent cerebral embolism, mycotic aneurysm, brain abscess, and meningitis are commonly diagnosed (Figure 1). Patients with MVE, especially when it is caused by $S$. aureus infection, might have sizeable $(\geq 15 \mathrm{~mm})$ mobile vegetations that carry an increased risk of symptomatic embolic events and are an independent predictor of mortality after surgery. Computed tomography (CT) and magnetic resonance imaging of the brain has high accuracy in evaluating cerebral abnormalities, including embolic events in MVE. 
Most effective strategies are often related to the timing of intervention. In fact, it is necessary to consider that in $60 \%$ of patients, ischemic and hemorrhagic stroke precede the diagnosis of infective endocarditis, inviting to reflect on the fact that early decisions might reduce the risk of neurological complications. In addition, other associated events as silent cerebral embolism, which are recurrent in $50 \%$ of the patients, transient ischemic attack, mycotic aneurysm, and brain abscess deserve specific consideration. Another criterion for early intervention is represented by the presence of vegetations owing to $S$. aureus infection that are large, mobile, and prominently located in the MV (Figure 1).

As we described previously, the strategy to be used in the treatment of MVE plays a crucial role in patient survival, and timing of surgery is the result of a shared multidisciplinary decision. Clinical and echocardiographic assessments help to establish the location of the infectious field, its extension, and its severity (ie, involvement of MV alone or aortic valve as well). The main issues to be addressed by the multidisciplinary team are the evidence of uncontrolled infection, heart failure, and prevention of embolism. Persistent fever for more than 5 to 7 days, without normalization of positive blood cultures, suggest an uncontrolled infection with potential for local abscess, large vegetation, false aneurysm, fistula, and dehiscence of prosthetic valve. In these cases, emergency surgery is strongly recommended. Conversely, when the infection is caused by fungi, multidrug-resistant organisms, or Pseudomonas aeruginosa, elective surgery may offer a valid solution.

Heart failure occurs in patients who have infection of the MV or extensive aortomitral localization of endocarditis with valvular dysfunction. Clinical evidence and echocardiographic findings might reveal severe acute regurgitation or obstruction of the MV associated with either a degree of cardiac failure easily controllable with medical treatment or pulmonary edema and cardiogenic shock that are not responsive to medical treatment. Some patients might also have a fistula into a cardiac chamber or pericardium. In case cardiac failure is manageable with medical treatment, elective surgery may be planned. Conversely, urgent surgery is required when there is a more severe degree of cardiac failure. When the patient shows signs of poor hemodynamic tolerance with early MV closure or pulmonary hypertension, emergent surgical treatment is indicated.

The only practicable surgical way to prevent embolism is emergency surgery. Manifestations of cardiac failure, persistent infection or abscess, involvement of the MV or aortomitral junction with vegetations larger than $10 \mathrm{~mm}$ or isolated very large vegetation larger than $15 \mathrm{~mm}$ are predisposing factors for embolism. The occurrence of one or more embolic events within the first 2 weeks of therapy suggests inadequate control of the infection.

In emergency surgery, treatment of the infected valve is required within 24 hours following completion of a diagnostic workup. Patients whose condition is considered urgent should receive surgery within a few days after it is indicated. Elective surgery should be performed after at least 1 to 2 weeks of antibiotic therapy. Type of surgery depends on the extension of the lesions; conservative surgery should be considered when only one leaflet or one scallop are involved, whereas mitral valve replacement is required for more extensive involvement of the valve.

\section{MULTIDISCIPLINARY SHARED DECISION MAKING IN THE CHOICE OF ALLOGENEIC MITRAL TISSUE}

Infection of the MV can involve the annulus, valve leaflets, chordae tendineae, and subvalvular apparatus. In cases of aggressive IE, lesions can sometimes extend to the papillary muscles and left ventricular wall. The migration of the infection from its original focus to the aortic valve tends to involve scallops $\mathrm{A} 1, \mathrm{~A} 2$, and $\mathrm{A} 3$ in the anterior leaflet, primarily in the A1 scallop next to the mitral-aortic junction. Infective localization on the leaflet might also result in leaflet perforation or inflammatory leaflet retraction. In cases of aortomitral curtain involvement or complex lesions, extensive replacement with allogeneic tissue might be considered.

A primary concern in valve replacement regards anticoagulation treatment in women of childbearing age. This issue is a strong argument for the use of mitral homograft. Avoidance of oral anticoagulation clearly facilitated normal pregnancies in our series. On the other hand, the structural deterioration of the mitral homograft occurred in two thirds of women who experienced pregnancy, with a trend similar to the one for bioprostheses. In our experience, the choice of a mitral homograft as a valve substitute was thought to be appropriate when most of the valve was involved and aggressive pathogens caused a destruction of a large part of the heart

The second concern to be discussed by the heart team concerns the patient's preference and willingness to undergo the operation. An extensive operation might be considered daunting by patients, and clinicians are required to explain in detail the steps of the procedure, the potential complications, and the postoperative course to provide sufficient information for the patient to make a conscious decision. Patient needs to be made aware of the complexity of the disease and of the potential need of extensive debridement to achieve good and stable results. Performing a quicker operation with a prosthetic valve within the context of a significant infective involvement of valve tissues provides an unstable situation with a high potential 
for infection recurrence. Any decision regarding surgery should be driven by a balance between the risk of the procedure and the benefit achievable. Considering the significant risk during endocarditis surgery and the even greater risk represented by a reoperation for reinfection in this context, we believe that the option to undergo a minimized operation with known potential for reinfection should be discouraged.

Patients need to be informed in detail regarding the technical issues pertaining to the use of a homograft. As recommended by current guidelines, multidisciplinary decision making regarding valve replacement strategies in IE should consider the longevity of the biological substitutes, the potential recurrence of infection, and the risk of repeated surgery, which is often associated with extensive heart demolition. This is not only required but also emphasized. The choices are best made across a process of shared decision making that comprehends the patient, the patient's family, an interventional cardiologist, a cardiac surgeon and, by preference, the patient's general cardiologist or primary care practitioner. In the contest of homograft implantation, a balance between the risk of
SVD with potential valve dysfunction $(17 \%$ to $20 \%$ at 8 years) versus a very low incidence of infection recurrence, which would require further complex redo surgery and tissue demolition, should be considered when discussing surgical options with patients.

Finally, the main problem in patients who are treated for complex valve endocarditis with MV involvement and extension in the mitral-aortic curtain is not structural valve deterioration, but the recurrence of infection. The reoperation for a relapsing infection carries a higher mortality than the reoperation for structural valve deterioration or dysfunction of an aortic homograft inserted in aortic root position $(4 \%-10 \%)$. We have to keep in mind that the extensive demolition of adherences is necessary to access the heart where the synthetic material was previously inserted and that the reoperation for redo endocarditis on a prosthetic valve is more challenging and riskier than for a previously implanted homograft. Indeed, the foreign material constituting the stent of mechanical or biological prosthetic valve elicits a strong inflammatory reaction and can result in stronger adherences complicating the operation. 


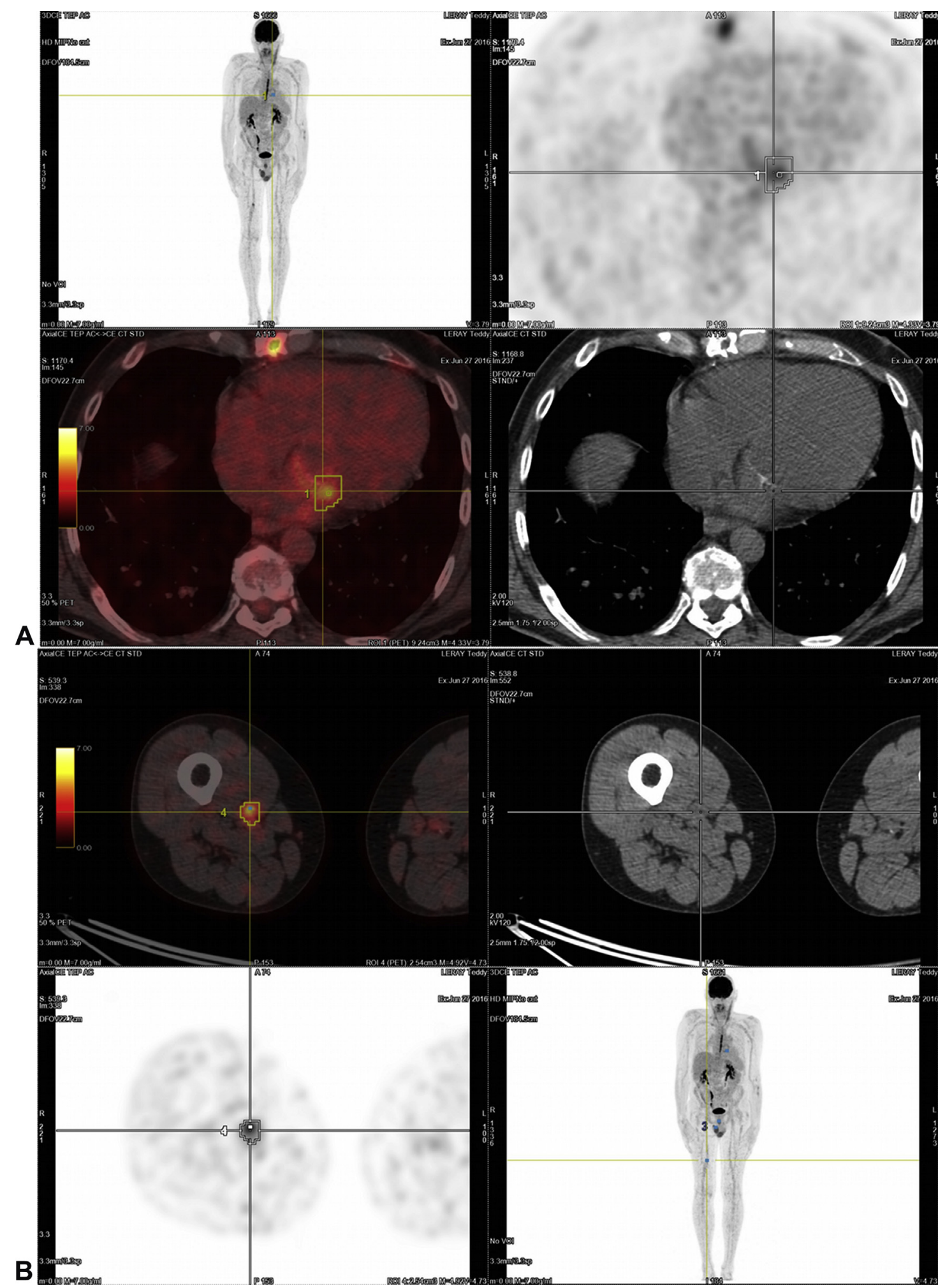

FIGURE E1. A, Fluorodeoxglucose-labelled leucocyte PET/CT of chest showing full body radionuclide accumulation and distribution (A1 top left), detail of radionuclide accumulation in the heart (infective focus, A2 top right), CT-PET gated image with quantitative color scale demonstrating the intensity of radionuclide accumulation at that specific site ( $\mathrm{A} 3$ bottom left), CT gated image of the heart ( $A 4$ bottom right). B, Fluorodeoxglucose-labelled leucocyte PET/CT of lower limb showing CT-PET gated image with quantitative color scale demonstrating the intensity of radionuclide accumulation at the level of right femoralis quadriceps muscle (septic embolus, B1 top left), CT gated image of the lower limb at the same level (B2 top right), detail of radionuclide accumulation in the lower limb (B3 bottom left), image of radionuclide accumulation and distribution in the full body (B4 bottom right). 